\title{
EL CULTO DE LA VIRGEN DE COPACABANA EN ESPAÑA Y LA FECHA DE COMPOSICIÓN DE LA AURORA EN COPACABANA ${ }^{1}$
}

\author{
José Elías Gutiérrez Meza \\ Staufenstr. 2 \\ 48145 Münster \\ Alemania \\ eliasgutierrezmeza@gmail.com
}

[Anuario calderoniano (ISSN: 1888-8046), 7, 2014, pp. 167-178]

La fecha más temprana que hasta el momento conocemos sobre la representación de La aurora en Copacabana (la única comedia indiana ${ }^{2}$ escrita por Calderón, en la cual dramatizó el descubrimiento, conquista y evangelización del Perú, siguiendo la historia de la talla de la Virgen de Copacabana y de su escultor indígena Francisco Tito Yupanqui) proviene de una anotación del Diario del Conde de Pötting, correspondiente al 16 de noviembre de 1669: «Fuime con la condesa a la comedia, del origen de Nuestra Señora de Copacabana en las

${ }^{1}$ El presente artículo supera un acercamiento anterior a este tema en Gutiérrez Meza, 2013.

${ }^{2}$ Sigo la definición de «comedia indiana» propuesta por Zugasti (1996, p. 432). 
Indias, asunto bellísimo» ${ }^{3}$. Sobre la fecha de su composición se han propuesto diversas hipótesis. Se la ha relacionado con la vida personal del poeta, considerando el cambio que supuso su ordenación sacerdotal en su producción teatral ${ }^{4}$, así como la presencia de un relicario de esta advocación mariana entre sus bienes ${ }^{5}$. También se ha intentado datarla a partir de sus rasgos métricos, temáticos y escenográficos ${ }^{6}$.

En la línea de las interpretaciones políticas de las comedias mitológicas se ha vinculado la comedia con ciertos acontecimientos de la

3 Nieto Nuño, 1993, p. 73. Pötting fue el representante diplomático en Madrid del emperador Leopoldo I entre 1664 y 1674.

${ }^{4}$ Para Hartzenbusch su composición no pudo ser posterior a 1651, pues la comedia no era una fiesta real, por lo que tuvo que ser escrita antes de la ordenación de Calderón, tras la cual solo escribió autos y fiestas reales (Calderón, Comedias, pp. 676-677). Pagés Larraya, sin afirmar o negar su calidad de fiesta, consideró 1651 como probable fecha de su composición (1958, p. 300). En cambio, para Valbuena Briones se trataba de una fiesta que Calderón debe haber compuesto entre 1654 y 1661 (Calderón, Obras completas, p. 1357). En la misma línea, Parker llamó la atención sobre el equívoco en su género: «Hartzenbusch was wrong in saying it was not a court play» y propuso que fue compuesta entre 1655 y 1665 (1983, p. 262). Una datación un poco más restringida, «a mediados o a finales de la década del 50», postuló Ruiz Ramón (1988, p. 132). Asimismo, Valbuena reformuló su datación, conjeturando que Calderón orientó su producción hacia la devoción mariana mientras esperaba la cédula de su ordenación, por lo que entre octubre de 1650 y setiembre de 1651 escribió La Virgen de los Remedios, La Virgen de la Almudena (primera y segunda parte) y La aurora en Copacabana (1977, pp. 199-200). Además de que las citadas comedias se encuentran pérdidas, las dos partes de La Virgen de la Almudena habrían sido compuestas en 1640 (Cotarelo, 2001, p. 205), de modo que se inscriben dentro del fervor mariano que caracterizó la década de los treinta (González Cañal, 2011, p. 285).

${ }^{5} \mathrm{La}$ crítica ha llamado la atención sobre la inclusión en el inventario de los bienes de Calderón de una «imagen» de la Virgen de Copacabana (Beutler, 1998, p. 68; Zugasti, 2001, p. 434; Eguiarte Bendímez, 2002, p. 194). Sobre su origen, Valbuena sugirió que habría llegado a manos del poeta por medio de su hermano Diego (1977, p. 200). Esta posibilidad ha sido desestimada por Aszyk, quien también ha cuestionado que la presencia de dicha imagen en el inventario (donde figuran muchas piezas de arte religioso de diferentes advocaciones) sea suficiente para extraer conclusiones sobre las preferencias de su propietario (2005, pp. 218-219).

${ }^{6}$ En su estudio sobre la versificación calderoniana, Hilborn databa la comedia alrededor de 1661 (1938, pp. 67-68). Su propuesta fue respaldada por Engling, para quien existen rasgos temáticos (Calderón, La aurora en Copacabana, pp. 50-52) y escenográficos (Shergold, 1967, pp. 367-369) que La aurora en Copacabana comparte con las comedias Apolo y Climene y El Faetonte (fechadas por Hilborn en 1661). 
vida cortesana durante la regencia de Mariana de Austria $^{7}$ y con el establecimiento y propagación del culto americano de la Virgen de Copacabana en Madrid. En esta última senda se ubica el presente trabajo, que indaga en la relación entre la expansión de dicho culto americano en España y la composición de La aurora en Copacabana.

Hill fue probablemente la primera en vincular la comedia con la dedicación de una capilla en Madrid a la Virgen de Copacabana en $1652^{8}$. En esta misma línea, Beutler y Dixon sugirieron la fecha de 1662, siguiendo lo anotado por fray Andrés de San Nicolás en el prólogo de su Imagen de Nuestra Señora de Copacabana $(1663)^{9}$ :

La ocasión de haberse colocado en este Convento de los Descalzos de Nuestro Padre San Agustín a veinte y uno de noviembre del año pasado de mil seiscientos y sesenta y dos, una imagen de Nuestra Señora de Copacabana, copia de aquella muy milagrosa que está en el corazón del Perú, animando como tal a sus partes y provincias, haya dado motivo para que $[\ldots]$ hayamos determinado referir $[\ldots]$ las grandezas de esta imagen $[\ldots]$.

Débese verdaderamente el principio y el aumento de que hoy goza en esta corte y otras partes al devoto pecho del reverendísimo padre maestro fray Miguel de Aguirre, catedrático de Prima de Escritura de la Universidad de Lima y calificador del Santo Oficio, hijo benemérito de la insigne provincia de nuestros padres observantes del Perú. Pues no contento con haber traído en su compañía, desde los apartados hemisferios de las Indias, una imagen tocada a la mesma de Copacabana y expuéstola para bien público y consuelo de los fieles en el religiosísimo Colegio llamado de doña María de Aragón, con expensas bien crecidas, cuando estuvo en Roma el año en que fue electo general de toda la Orden el

${ }^{7}$ Hernández Araico (en su lectura de La aurora en Copacabana como comedia mitológica que representa un «mito nacional que resulta más intangible después de la muerte de Felipe IV, durante la crisis que ocasiona, más que de la monarquía, del teatro mismo») la fecha en 1667 (1996, p. 268), año de la reapertura de los teatros comerciales, cerrados en setiembre de 1665 por Mariana de Austria debido a la muerte de Felipe IV (Varey y Shergold, 1975, p. 13). Tomando en cuenta esta sugerencia y el dato de Pötting, Zugasti postuló que la comedia fue compuesta entre 1667 y 1669 (2006, p. 651).

${ }^{8}$ Hill, 1976, p. 253.

${ }^{9}$ Beutler, 1998, pp. 67-68; Dixon, 1998, p. 265. Aunque Beutler no menciona la obra de San Nicolás (de la que Dixon parte para su datación), la investigadora sigue a García Álvarez, quien sí cita al fraile (1980-1981, p. 186). 
reverendísimo padre maestro fray Pablo Luchino de Pesaro, puso otra con solemne ostentación en nuestro Hospicio de San Ildefonso, celebrando allí la misa el ilustrísimo y reverendísimo señor don fray Ambrosio Landucio, obispo de Porfirio y dignísimo sacristán pontificio.

Causó esta fiesta con la relación de la recién conocida señora tal fervor en la piedad del Duque de Sermoneta, don Francisco Caetano, que haciendo sacar de ella un transumpto muy al vivo, le tuvo en su palacio, con tanta fe y reverencia que luego comenzó a manifestar Dios en él maravillas superiores, según consta de una información hecha en la villa de Cisternas el año de mil y seiscientos y sesenta ante Jacobo Catenas de Nomento.

Después en España el mismo reverendísimo padre maestro fray Miguel de Aguirre determinó poner otro, como lo hizo en nuestro Colegio de Alcalá de Henares, reservando por remate, al parecer, todo el resto de su afecto para echarlo aquí en Madrid con la fábrica de la sumptuosa capilla que desde los fundamentos ha levantado en honra y gloria de laVirgen, su abogada, eternizando así su nombre según aquello de Ovidio: Et memorem famam, qui bene cessit habet.

De este modo, al parecer de Dixon: «This volume not only must be regarded as another possible source of our play, but more interestingly suggests that the latter may have been commissioned to celebrate the same event» ${ }^{10}$. Sin embargo, como se desprende del citado prólogo, esta no fue la única imagen que se entronizó en Madrid ni en España. Al respecto, el prólogo introduce el nombre de un personaje importantísimo en la difusión del culto de la Virgen de Copacabana en España: Miguel de Aguirre. Este fraile nació en La Plata (actual Sucre, Bolivia) en 1598 y vistió el hábito agustino en 1613. En 1639 se trasladó a Lima, donde se convirtió en confesor y consejero de Pedro de Toledo y Leiva, marqués de Mancera y, por ese entonces, virrey del Perú. En 1645 acompañó al hijo de este, Antonio Sebastián de Toledo y Leiva, en la expedición que dirigió a Valdivia, como parte de la defensa y fortificación de los principales puertos peruanos contra los ataques de los piratas holandeses ${ }^{11}$. En dicha ocasión, Aguirre dio la primera muestra de su devoción por esta advoca-

${ }^{10}$ Dixon, 1998, p. 265.

11 Maturana, 1904, p. 661; Medina, 1965, p. 463. 
ción mariana: "pues allí mismo escogió el más bello paraje para levantar una ara a Nuestra Señora de Copacabana» ${ }^{12}$.

En 1650 llegó a Madrid en compañía del marqués de Mancera e instaló en el Colegio de doña María de Aragón la primera imagen de la Virgen de Copacabana ${ }^{13}$. Después hizo dedicarle un altar del Convento de San Felipe el Real ${ }^{14}$; instaló una imagen en el Hospicio de San Ildefonso en Roma (8 de setiembre de 1655$)^{15}$ y otra en el Colegio de Alcalá de Henares; y consiguió que se levantase una capilla en el Convento de los Agustinos Descalzos o de Copacabana ${ }^{16}$ (21 de noviembre de 1662 , motivo de la citada obra de San Nicolás) ${ }^{17}$. Su muerte se produjo en 1664, cuando preparaba la instalación de otra imagen en Mancera, la villa de su protector ${ }^{18}$.

12 Maturana, 1904, pp. 662-663. Resultado de esta experiencia fue su libro: Población de Valdivia. Motivos y medios para aquella fundación. Defensas del Reino del Perú para resistir las invasiones enemigas en mar y tierra. Paces pedidas por los indios rebeldes de Chile, aceptadas y capituladas por el gobernador y estado que tienen hasta el 2 de abril del año 1647, Lima, Jorge López de Herrera, 1647.

${ }^{13}$ Calancha, Crónicas agustinianas del Perú,p. 661. A esta primera imagen se referiría Hill y también Gisbert, para quien Calderón tuvo que informarse de Aguirre: «quien era testigo fidedigno tanto por pertenecer a la zona como por su relación con Calancha y, a su vez, como conocedor de la obra de Ramos» (Gisbert, 1984, p. 27).

14 Santiago Vela, 1913, vol. I, p. 61.

15 Marraccio, 1656, p. 29.

16 «En el plano Texeira de Madrid, 1656, el paseo ante el convento recibe el nombre de "Prado de los Recoletos Agustinos"; sin embargo, casi nadie en Madrid lo conocía con este nombre sino: "Paseo de Copacabana", así como "Convento de Copacabana”, "Prior de Copacabana”, etc.» (García Álvarez, 1980-1981, p. 186).

${ }^{17}$ La elección de dichos sitios obedeció a su paso por Roma como procurador de su provincia y a los problemas que tuvo para establecerse en el Convento de los Agustinos Descalzos de Madrid (San Francisco de Asís, Historia general de los Padres Agustinos Descalzos, p. 70).Vivió ahí desde el 31 de marzo de 1660 hasta su muerte (Santa Teresa, Historia general de los Padres Agustinos Descalzos, p. 556).

18 Luis de Jesús, Sermón en las solemnes honras, fol. 6r. El marqués de Mancera murió en 1654 y dejó a Aguirre como albacea en su testamento (Maturana, 1904, p. 668). Asimismo, existen noticias de la instalación de más imágenes de la Virgen, pero sin mención de la participación directa de Aguirre. Gabriel de León, en su Compendio de la esclarecida y gloriosa imagen de Nuestra Señora de Copacabana (p. 411), se refiere a dos, instaladas en Irún (Vizcaya) y en Mansilla (cerca de León); y por el título de la Oración del fraile agustino José de la Encarnación, se instaló otra en el Convento de los Agustinos Recoletos de Toledo en 1688 (Simón Díaz, 1982, pp. 265-266). A es- 
La propagación del culto de la Virgen de Copacabana, a instancias de Aguirre ${ }^{19}$, en España nos lleva a repensar las sugerencias de Hill, Beutler y Dixon. Si bien el posible vínculo entre La aurora en Copacabana y las citadas entronizaciones es una hipótesis verosímil, ante la falta de datos más precisos que nos permitan ligar la comedia a alguna de ellas deviene en un criterio insuficiente para su datación, ya que entre 1652 y 1664 se colocaron múltiples imágenes de dicha advocación y, al menos, tres de ellas se ubicaron en Madrid. Con esto no pretendo negar que tal vínculo exista; por el contrario, dichas entronizaciones evidencian el fervor que se vivió durante esos años en España hacia la Virgen americana y con el que, de algún modo, está relacionada la comedia. Además, si hasta este punto he mostrado la activa participación que tuvo Aguirre en la expansión de dicho culto, el mismo también recibió el patrocinio de una importante institución gubernamental vinculada con sus orígenes ultramarinos: el Consejo Real y Supremo de las Indias.

El 18 de julio de 1655 los galeones de la plata procedentes de Cartagena escaparon milagrosamente, cerca de Cuba, del peligro de ser capturados por la flota inglesa. Dos días después se salvaron, también por milagro, los navíos que llevaban los tesoros de la Nueva España. Días después, el 23 de julio, la flota inglesa apareció delante del puerto de La Habana, donde estaban reunidas las flotas españolas, pero no llegó a distinguir ni un solo barco, así que volvió a Europa sin haber conseguido ninguna presa. Esta «triple coincidencia de circunstancias felices» se atribuyó a que el 18 de agosto el Consejo de Indias había hecho una rogativa a la Virgen de Copacabana; por ello, el 8 de noviembre dirigió una consulta a Felipe IV, en la que proponía se celebrase cada 18 de julio una fiesta religiosa en el Convento

tas hay que añadir la encargada por el duque de Sermoneta para su palacio en Cisternas (Italia), incluida en el prólogo de San Nicolás.

${ }^{19}$ Junto con las imágenes, Aguirre también repartió láminas de la Virgen: «iCuántas láminas hizo abrir para repartir estampas! [...] No había pared de iglesia o esquina de calle que no le pareciese bien para poner imágenes de María. Yo le solía decir: “Padre, maestro, ¿por qué pone vuestra paternidad tantas imágenes?”; y me respondía: "A lo menos el que las vea les hará una cortesía y rezará un Avemaría o un Salve"” (Luis de Jesús, Sermón en las solemnes honras, fol. 8r). 
de doña María de Aragón «en acción de gracias y en perpetua memoria de estos sucesos ${ }^{20}$.

La institución de esta fiesta anual en 1656 evidencia la importancia que consiguió este culto mariano, la cual se extiende hasta, por lo menos, principios de los setenta ${ }^{21}$. En todo caso, las múltiples entronizaciones de imágenes y la dedicación de una fiesta anual aumentan el número de escenarios posibles ${ }^{22}$ al que pudo estar destinada $L a$ aurora en Copacabana, sin aportar datos que nos permitan delimitar más su datación. Sin embargo, hay un aspecto de la promoción de este culto mariano que nos puede ayudar a precisar la fecha de su composición. Me refiero a los libros que aparecen en estos años, algunos de ellos encargados por Aguirre:

En Roma, a instancia suya, escribió un libro de la imagen de Copacabana el eruditísimo padre Hipólito Marracio; en este convento [Recoletos Agustinos de Madrid] acabó con un religioso [San Nicolás] que escribiese otro del mesmo asunto (Luis de Jesús, Sermón en las solemnes honras, fol. 8r).

El libro de Marracio es De diva Virgine Copacabana in peruano Novi Mundi Regno celebérrima (Roma, 1656) y el religioso al que Luis de Jesús se refiere es San Nicolás, quien vivía en el Convento de los Agustinos Descalzos y fue autor de la ya citada Imagen de Nuestra Señora de Copacabana. A estos libros se suman las siguientes obras, todas de

${ }^{20}$ Aquí he resumido los datos que recoge Schäfer (1935, pp. 296-298).

21 «Parece que esta fiesta fue muy preferida, pues hallamos que en 1671 se celebró hasta dos veces, en 18 de julio y en 9 de octubre, la segunda vez con sermón del padre agustino fray Cipriano de Herrera» (Schäfer, 1935, p. 298).

22 Sobre la primera celebración de esta fiesta, Schäfer señala: «Acompañado por los seis pajes del presidente que llevan grandes hachas de cera, el Consejo de Indias entero hace su entrada solemne, tomando asiento en el estrado tapizado con hierba fresca, para asistir a la misa en acción de gracias, realzada por la música de la célebre Capilla Real del Monasterio de la Encarnación» (1935, p. 298). En la comedia, la acotación de la apoteosis final: " $y$ en forma de capilla, cantando delante los músicos, dará vuelta en hombros al tablado la imagen» (v. 4296 acot.), ¿dicha «capilla» podría referirse a la Capilla Real, la cual, asimismo, también participó en la instalación de la imagen del Colegio de María de Alvarado en 1652 (Calancha, Crónicas agustinianas del Perú, p. 661)? 
frailes agustinos: la Historia del Santuario de Nuestra Señora de Copacabana (1621) de Ramos Gavilán, la Crónica moralizadora del Orden de San Agustín en el Perú (1639) de Antonio de Calancha ${ }^{23}$, el poema sacro Santuario de Nuestra Señora de Copacabana en el Perú (1641) de Fernando de Valverde y el Compendio de la esclarecida y gloriosa imagen de Nuestra Señora de Copacabana (1663) de Gabriel de León ${ }^{24}$.

Tal proliferación de obras dedicadas a la Virgen americana lleva a Santiago Vela a afirmar que San Nicolás abordó «un asunto tan trillado» ${ }^{25}$, lo que el mismo autor confirma en su prólogo, donde recoge las diversas obras dedicadas o en las que se hace referencia a esta advocación mariana:

no obstante el haber ya escrito de esta efigie soberana los padres fray Alonso Ramos Gavilán, maestro fray Fernando de Valverde, maestro fray Antonio de la Calancha, padre Hipólito Marraccio y agora poco ha el padre fray Gabriel de León; fuera de los que en sus obras han hecho memoria de tan prodigioso retrato como son Félix Astolfi, Francisco Benci, Juan Bonifacio, Antonio de León Pinelo, fray Joaquín Brullo y otros muchos que se omite.

En esta lista, que incluye textos de distintos géneros (crónica, compendio, poema), La aurora en Copacabana de Calderón brilla por su ausencia, omisión que solo puede deberse a que hasta finales de 1663

23 Aunque de tema más amplio, recoge con detalle la historia de la Virgen, siguiendo a Ramos Gavilán.

24 Como lo explicita su título, es una breve exposición de lo más sustancial de la historia de la Virgen de Copacabana, cuya fuente es la crónica de Calancha. De ahí que fray Luis Criado en su aprobación le agradezca: «habernos dado sin digresiones, ponderaciones, ni entreverado materias diferentes, lo que deseaban los devotos y esclavos de esta Serenísima Reina, que era saber líquida y puramente su origen y milagros».

25 Santiago Vela, 1925, vol.VII, p. 225. Aunque su asunto principal no es el culto mariano, la Noticia del recibimiento y entrada de la Reina Nuestra Señora Doña María Ana de Austria en la muy noble y leal coronada Villa de Madrid (1650) se ha vinculado con la composición de La aurora en Copacabana, porque en el arco que representaba al Nuevo Mundo aparecía pintada la intervención de la Virgen en el cerco del Cuzco, la cual coincide en muchos aspectos con la representación del mismo milagro en la comedia. Por ello, Lohmann Villena sugirió que la Noticia fue la fuente de inspiración del poeta y que San Nicolás escribió su libro: «incitado por alguna representación de la obra calderoniana?» (1972, p. 71), sugerencia rebatida por Rípodas (1995, p. 58). 
(fecha en la que fue publicada la obra de San Nicolás) la comedia no se había representado.

A modo de conclusión, primero, no hay lugar a dudas de que el culto americano de la Virgen de Copacabana durante los años analizados vivió en España un «momento estelar»: se colocaron múltiples imágenes, se formaron cofradías, se estableció una celebración anual y se publicaron diversas obras de devoción ${ }^{26}$. En tal sentido, resultaría extraño que La aurora en Copacabana estuviese desligada de dicho auge ${ }^{27}$; por el contrario, debió ser resultado del mismo: ya sea como un encargo que el propio Aguirre $\mathrm{u}$ otro devoto de esta advocación hizo a Calderón, ya sea a iniciativa del poeta, quien, como lo prueba el escapulario de plata que poseía, no fue ajeno a dicha devoción. Lamentablemente hasta el momento no contamos con datos que nos permitan precisar tales circunstancias. Sin embargo, gracias a la lista de San Nicolás y la noticia de su representación en el diario de Pötting, podemos sostener que la composición de la comedia debió de producirse entre 1664 y 1669, período que se puede restringir más si consideramos la interrupción de la actividad teatral entre setiembre de 1665 y mayo de $1667^{28}$.

A mi parecer, Calderón escribió La aurora en Copacabana entre 1664 y 1665 por la cercanía de estas fechas con la campaña de promoción de dicho culto dirigida por Aguirre y con el año propuesto por Hilborn (1661) a partir de la versificación de la comedia ${ }^{29}$. Al igual que sucedió con El Faetonte ${ }^{30}$, su estreno (y no su composición) se pudo haber pospuesto hasta el reinicio de la actividad teatral en 1667 debido a ciertos acontecimientos como la muerte de Aguirre (el más probable responsable del encargo) y la de Felipe IV.

26 Rípodas, 1995, p. 48.

27 Para Hernández Araico, la comedia iría más allá de la celebración de la advocación mariana: «se vislumbran sugerencias de una intencionalidad más sagaz en Calderón que un simple dogmatismo adulador de la adopción americana del culto mariano que no cumpliera ningún propósito especial en función de la corte y en beneficio personal o profesional del dramaturgo" (1996, p. 252).

${ }^{28}$ Varey y Shergold, 1975, p. 13.

29 «El trabajo de Hilborn, con todos los reparos que quieran hacérsele, sigue siendo un instrumento muy eficaz» para sugerir la fecha de escritura de una obra (Iglesias Feijoo y Ulla Lorenzo, 2010, p. 176).

${ }^{30}$ Iglesias Feijoo y Ulla Lorenzo, 2010. 


\section{Bibliografía}

Aszyk, U., "La aurora en Copacabana de Calderón de la Barca: en torno a las fuentes de inspiración», en Actas del Congreso "El Siglo de Oro en el nuevo milenio», ed. C. Mata y M. Zugasti, Pamplona, EUNSA, 2005, vol. I, pp. 217-230.

Beutler, G., «Pedro Calderón de la Barca: La aurora en Copacabana», en Texto e imagen en Calderón. Undécimo Coloquio Anglogermano sobre Calderón, ed. M. Tietz, Stuttgart, Steiner, 1998, pp. 63-74.

Calancha, A. de la y B. Torres, Crónicas agustinianas del Perú, ed. M. Merino, Madrid, Centro Superior de Investigaciones Científicas, 1972, vol. I.

Calderón de la Barca, P., La aurora en Copacabana, ed. E. Engling, London, Tamesis, 1994.

- La aurora en Copacabana, ed. J. E. Gutiérrez Meza, Pamplona, Universidad de Navarra, Tesis doctoral, 2012.

- Comedias, ed. J. E. Hartzenbusch, Madrid, Manuel Rivadeneyra, 1858, vol. IV.

- Obras completas I. Dramas, ed. Á. Valbuena Briones, Madrid, Aguilar, 1959.

Cotarelo y Mori, E., Ensayo sobre la vida y obras de D. Pedro Calderón de la Barca, ed. I. Arellano y J. M. Escudero, Madrid / Frankfurt, Iberoamericana / Vervuert, 2001.

Dixon, V., «Review» a la ed. de La aurora en Copacabana de E. Engling, Bulletin of Hispanic Studies, 75, 1998, pp. 264-266.

Eguiarte Bendímez, E., "América dentro de la obra de Calderón de la Barca: La aurora en Copacabana», en Calderón 2000. Actas del Congreso Internacional "IV Centenario del nacimiento de Calderón», ed. I. Arellano, Kassel, Reichenberger, 2002, vol. 2, pp. 181-196.

García Álvarez, C., «Las fuentes de La aurora en Copacabana de Calderón de la Barca», Revista Chilena de Literatura, 16-17, 1980-1981, pp. 179-213.

Gisbert, T., «El ídolo de Copacabana. La Virgen María y el mundo mítico de los aymaras», Yachay, 1, 1984, pp. 25-39.

González Cañal, R., "La Virgen de Atocha en el teatro español del Siglo de Oro", en Actas del I Congreso Ibero-Asiático de Hispanistas Siglo de Oro e Hispanismo general, ed. M. Insúa y V. Maurya, Pamplona, Publicaciones Digitales del GRISO / Universidad de Navarra, 2011, pp. 279-293.

Gutiérrez Meza, J. E., «Notas sobre la fecha de composición de La aurora en Copacabana de Calderón", en Pictavia aurea. Actas del IX Congreso de la Asociación Internacional «Siglo de Oro», ed. A. Bègue y E. Herrán Alonso, Toulouse, Presses Universitaires du Mirail, 2013, pp. 891-899.

Hernández Araico, S., «La teatralización calderoniana de un mito americanohispano: La aurora en Copacabana, compendio de recursos teatrales en oportuna escenificación", en Mira de Amescua en Candelero. Actas del 
Congreso Internacional sobre Mira de Amescua y el teatro español del siglo XVII, ed. A. de la Granja y J. A. Martínez Berbel, Granada, Universidad de Granada, 1996, vol. II, pp. 251-268.

Hilborn, H., A Chronology of the Plays of Pedro Calderón de la Barca, Toronto, University of Toronto Press, 1938.

Hill, J. M., Calderon's "La aurora en Copacabana»: A Figural Interpretation, Lexington, University of Kentucky, 1976.

Iglesias Feijoo, L. y A. Ulla Lorenzo, «Las fechas de El Faetonte de Calderón», Anuario Calderoniano, 3, 2010, pp. 173-198.

León, G. de, Compendio del origen de la esclarecida y milagrosa imagen de Nuestra Señora de Copacabana, Patrona del Perú, Madrid, Pedro de Val, 1663.

Lohmann Villena, G., "Las fuentes de inspiración de una obra teatral de Calderón de la Barca sobre el Perú», Fénix, 22, 1972, pp. 69-73.

LUIS DE JEsús, Sermón en las solemnes honras que el religiosísimo convento de Recoletos Agustinos de Madrid hizo al reverendísimo P. M. F. Miguel de Aguirre, Madrid, Juan Nogués, 1664.

Marraccio, H., De diva Virgine Copacabana in peruano Novi Mundi Regno celeberrima, Roma, Haed Colinij, 1656.

Maturana, V., Historia de los agustinos en Chile, Santiago de Chile, Imprenta Valparaíso de Federico Lathrop, 1904, vol. I.

Medina, J. T., Biblioteca hispano-chilena (1523-1817), Amsterdam, N. Israel, 1965, vol. I.

Nieto Nuño, M. (ed.), Diario del Conde de Pötting, embajador del Sacro Imperio en Madrid (1664-1674), Madrid, Biblioteca Diplomática Española, 1993, vol. II.

Pagés Larraya, A., «El Nuevo Mundo en una obra de Calderón», Cuadernos Hispanoamericanos, 170, 1958, pp. 299-319.

PARker, A., "The New World in the autos sacramentales of Calderón», en Aureum Saeculum Hispanum. Beiträge zu Texten des Siglo de Oro. Festschrift für Hans Flasche zum 70. Geburtstag, ed. K.-H. Körner y D. Briesemeister, Wiesbaden, Steiner, 1983, pp. 261-269.

Ramos Gavilán, A., Historia del Santuario de Nuestra Señora de Copacabana, ed. I. Prado, Lima, Talleres Gráficos P. L. Villanueva, 1988.

Rípodas Ardanaz, D., «Presencia de América en la España del Seiscientos. El culto a la Virgen de Copacabana», Páginas sobre Hispanoamérica Colonial. Sociedad y Cultura, 2, 1995, pp. 47-78.

Ruiz Ramón, F., Celebración y catarsis (leer el teatro español), Murcia, Universidad de Murcia, 1988.

San Francisco de Asís, P. de, Historia general de los Padres Agustinos Descalzos del Orden de los Ermitaños del gran padre y doctor de la Iglesia San Agustín de la Congregación de España y de las Indias, coord. P. de San Francisco de Asís, Zaragoza, Francisco Moreno, 1756, vol. IV. 
San Nicolás, A. de, Imagen de Nuestra Señora de Copacabana, portento del Nuevo Mundo ya conocido en Europa, Madrid, Andrés García de la Iglesia, 1663.

Santa Teresa, D. de, Historia general de los Padres Agustinos Descalzos del Orden de los Ermitaños del gran padre y doctor de la Iglesia San Agustín de la Congregación de España y de las Indias, coord. P. de San Francisco de Asís, Barcelona, Herederos de Juan Pablo y María Martí, 1743, vol. III.

Santiago Vela, G. de, Ensayo de una biblioteca iberoamericana de la Orden de San Agustín, Madrid, Imprenta del Asilo de Huérfanos del Sagrado Corazón de Jesús, 1913-1931, 7 vols.

Schäfer, E., El Consejo Real y Supremo de las Indias, Sevilla, M. Carmona, 1935, vol. I.

Shergold, N. D., A History of the Spanish Stage from Medieval Times until the End of the Seventeenth Century, Oxford, Clarendon Press, 1967.

Simón DíAz, J., Bibliografía de la literatura hispánica, Madrid, Centro Superior de Investigaciones Científicas, 1982, vol. XII.

Valbuena Briones, Á., «La visión del mundo incaico en el teatro de Calderón», Arbor, 383, 1977, pp. 199-213.

Varey, J. E. y N. D. Shergold, Teatros y comedias en Madrid: 1666-1687. Estudio $y$ documentos, London, Tamesis, 1975.

Zugasti, M., "Notas para un repertorio de comedias indianas del Siglo de Oro", en Studia aurea. Actas del III Congreso de la AISO, ed. I. Arellano, C. Pinillos, F. Serralta y M. Vitse, Pamplona, GRISO / LEMSO, 1996, vol. II, pp. 429-442.

- «De iconografia mariana en dos comedias del Siglo de Oro: La Virgen de los Reyes de Hipólito de Vergara y La aurora en Copacabana de Calderón", en Calderón. Innovación y legado. Actas selectas del IX Congreso de la Asociación Internacional de Teatro Español y Novohispano de los Siglos de Oro, ed. I. Arellano y G.Vega García-Luengos, New York, Peter Lang, 2001, pp. 425450 .

- «La elaboración del icono de la Virgen de los Reyes en el auto calderoniano El santo rey don Fernando (Segunda parte)", en La dramaturgia de Calderón. Técnicas y estructuras (Homenaje a Jesús Sepúlveda), ed. I. Arellano y E. Cancelliere, Madrid / Frankfurt, Iberoamericana / Vervuert, 2006, pp. 637-666. 